Archive for

Organic Chemistry

Arkivoc 2018, part iv, 94-101

\title{
The reaction of sydnones with bromine in acetic anhydride revisited: a new route to 5-substituted-3-aryl-1,3,4-oxadiazol-2(3H)-ones from $\mathrm{N}$-aryl- $\mathrm{N}$-bromocarbonylhydrazines
}

Jonathan M. Tumey, Thijs Gerritsen, Jimmy Klaasen, Karunakar R. Madaram, and Kenneth Turnbull* Department of Chemistry, Wright State University, 3640 Colonel Glenn Hwy, Dayton, OH 45435, USA

E-mail: kenneth.turnbull@wright.edu

Dedicated to Prof. Gordon Gribble upon the occasion of his retirement from Dartmouth College Received 01-19-2018

Accepted 02-12-2018

Published on line 03-04-2018

\section{Abstract}

The reaction of 3-phenylsydnone with bromine in acetic anhydride to form 5-methyl-3-phenyl-1,3,4-oxadiazol$2(3 \mathrm{H})$-one has been reexamined and improved. A new mechanism involving a bromocarbonylhydrazine species is proposed and its intermediacy is supported by the observation that it reacts with acetic anhydride to yield the corresponding 1,3,4-oxadiazol-2(3H)-one. The process has been expanded to the use of acid chlorides and a novel synthesis of 5-substituted-3-aryl-1,3,4-oxadiazol-2(3H)-ones has been developed.

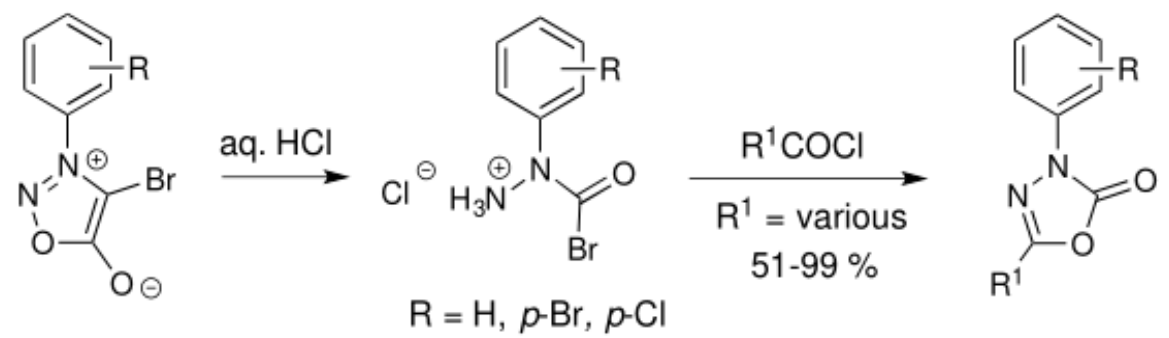

Keywords: 1,3,4-Oxadiazol-2(3H)-ones, sydnones, $\mathrm{N}$-aryl- $\mathrm{N}$-bromocarbonylhydrazines, bromine 


\section{Introduction}

Sydnones (c.f. 1) are members of the class of compounds known as mesoionic and have been studied extensively. ${ }^{1}$ In 1946, Kenner and Mackay prepared 4-bromo-3-phenylsydnone (2, R $\left.=\mathrm{H}\right)$ from the reaction of 3-phenylsydnone $(1, R=H)$ with bromine in acetic acid. ${ }^{2}$ Later, Baker, Ollis and Poole modified the process to use acetic anhydride as solvent. ${ }^{3}$ However, when Stansfield ${ }^{4}$ utilized the latter protocol he observed a vigorous evolution of gas at $30-40{ }^{\circ} \mathrm{C}$ and he isolated 5-methyl-3-phenyl-1,3,4-oxadiazol-2(3H)-one (3a) instead of the bromosydnone $2(R=H)$ [Scheme 1, route a]. Over 40 years later, Badami et al. extended the process to the synthesis of a variety of 5-methyl-3-aryl-1,3,4-oxadiazol-2(3H)-ones $(3, \mathrm{R}=\text { various })^{5}$ and they proposed a mechanism involving a 1,3-dipolar cycloaddition between $\mathbf{2}$ and the carbonyl group of the anhydride. They later concluded that $\mathrm{HBr}$, which is formed in situ, is important for the process, but only as a catalyst for the 1,3-dipolar cycloaddition mechanism. ${ }^{6}$ These mechanistic suggestions are surprising, especially since Yeh et al. ${ }^{7}$ showed in 1994 that treatment of 4-bromo-3-phenylsydnone $(2, \mathrm{R}=\mathrm{H})$ with $\mathrm{HX}(\mathrm{X}=\mathrm{Cl}, \mathrm{Br})$ cleaves the ring to form an isolable bromocarbonyl hydrazine derivative $(4, R=H)$. Given Yeh's results, it seemed likely to us that, rather than an unprecedented 1,3-dipolar cycloaddition process, the formation of the 1,3,4-oxadiazol$2(3 H)$ )-ones 3 (from 1 ) instead involves the intermediacy of the corresponding bromocarbonyl hydrazine species 4 (via reaction of $\mathbf{2}$ with $\mathrm{HBr}$ formed in situ) and subsequent reaction of the latter with acetic anhydride (Scheme 1, route b).

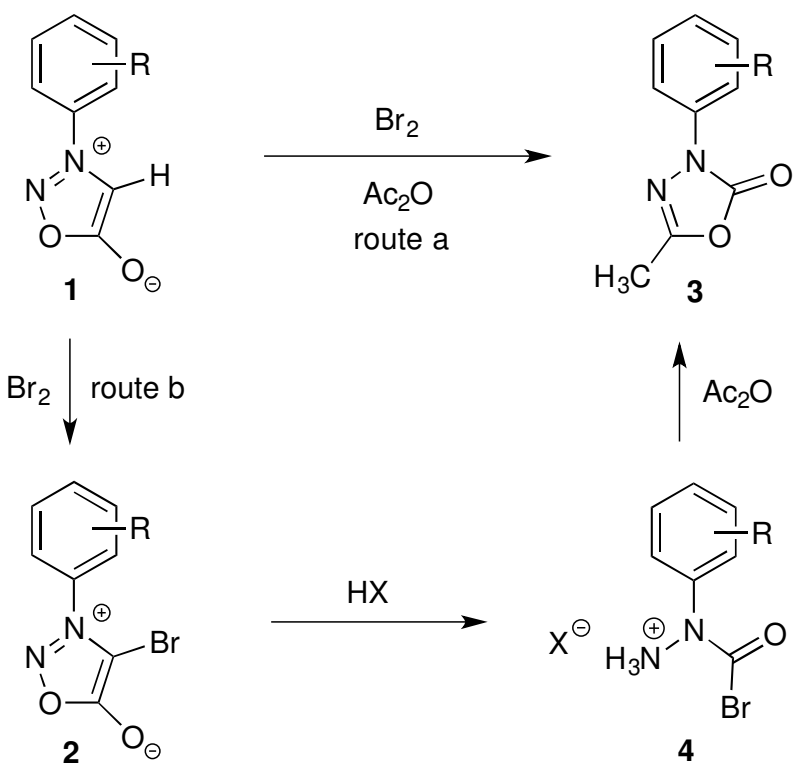

Scheme 1. The reaction of sydnones with $\mathrm{Br}_{2}$ in $\mathrm{Ac}_{2} \mathrm{O}$.

The present work was undertaken to reinvestigate this transformation, initially, by preparing the bromocarbonylhydrazine salt $(4, \mathrm{R}=\mathrm{H}, \mathrm{X}=\mathrm{Cl})$ from 4-bromo-3-phenylsydnone $(\mathbf{2}, \mathrm{R}=\mathrm{H})$ and allowing it to react with acetic anhydride in the expectation that 5-methyl-3-phenyl-1,3,4-oxadiazol-2(3H)-one (3a) would result. If so, this avenue would be extended to the formation of different 5-substituted-3-phenyl-1,3,4oxadiazol-2(3H)-ones ( $3, \mathrm{R}=$ various) by the use of a variety of acid chlorides. The 1,3,4-oxadiazol-2(3H)-one core is found in a diverse array of bioactive species and 3,5-disubstituted examples have attracted considerable attention. Inter alia, such species exhibit protoporphyrinogen oxidase inhibition, ${ }^{8}$ especially for herbicidal activity [e.g. oxadiazon ${ }^{9}$ and oxadiargy ${ }^{10}$ ], monoamine oxidase $\mathrm{B}$ inhibition, ${ }^{11}$ fungicidal activity, ${ }^{12}$ 
hormone-sensitive lipase inhibition, ${ }^{13} \mathrm{Ca}^{2+}$-activated potassium channel opening (BMS-191011), ${ }^{14}$ antimycobacterial activity (NCS 130852) ${ }^{15}$ and ABHD6 inhibition (3-substituted 5-alkoxy derivatives). ${ }^{16}$ 3,5Disubstituted 1,3,4-oxadiazol-2(3H)-ones have been prepared by a variety of methods, many of which involve the reaction of hydrazide derivatives with phosgene ${ }^{16-18}$ or involved procedures. ${ }^{19,20}$ More recently, 3,5disubstituted oxadiazolinones have been prepared via alkylation of 2-ethoxy-1,3,4-oxadiazoles, ${ }^{21}$ Pd-catalyzed carbonylation of hydrazides ${ }^{22,23}$ and 1,3-dipolar cycloaddition of nitrile imines with carbon dioxide. ${ }^{9}$

\section{Results and Discussion}

First, it was important to reproduce the reported synthesis of 3a [Scheme 1, route a], to provide an authentic sample of the product and to act as a benchmark for the process. Using the reported conditions (bromine in acetic anhydride added to $1(\mathrm{R}=\mathrm{H})$ at $0{ }^{\circ} \mathrm{C}$, warming to $60^{\circ} \mathrm{C}$, then addition to water and standing overnight) afforded $3 a$ in low yield and purity and two recrystallizations were required to afford pure product. The structure of the isolated product was confirmed as $3 a$ from its ${ }^{1} \mathrm{H}-\mathrm{NMR}$ and ${ }^{13} \mathrm{C}-\mathrm{NMR}$ spectra, however, extra peaks, most noticeably a singlet at $\delta 4.27$ in the ${ }^{1} \mathrm{H}$-NMR spectrum, were present in the crude material and, after analysis by GC-MS, it was concluded that these were due to the presence of 5-bromomethyl-3-phenyl1,3,4-oxadiazol-2(3H)-one (3b). Indeed, separation by column chromatography allowed for complete analysis of the by-product $\left({ }^{1} \mathrm{H}-\mathrm{NMR},{ }^{13} \mathrm{C}-\mathrm{NMR}, \mathrm{GC}-\mathrm{MS}\right)$ and its identity as $\mathbf{3 b}$ was confirmed by its independent synthesis from the reaction of the hydrazine salt $4(\mathrm{R}=\mathrm{H}, \mathrm{X}=\mathrm{Cl}$ ) with bromoacetyl chloride (vide infra, Scheme $2, \mathrm{R}^{1}=\mathrm{BrCH}_{2}$; Table 1, Entry 2). Modifications to the initial procedure demonstrated that the amount of byproduct could be reduced drastically and that 3 a could be obtained with $<2 \%$ impurity before recrystallization ( $<0.5 \%$ after recrystallization; GC/MS analysis). It is probable that $\mathbf{3 b}$ arises from $\alpha$-bromination of the acetic anhydride to form both mono- and di-bromoacetic anhydrides, which then react competitively with the bromocarbonylhydrazine intermediate $4(\mathrm{R}=\mathrm{H})$.

With a quantity of the desired oxadiazolone $3 a$ in hand, we turned now to the mechanism of the transformation shown in Scheme 1, path a. Since we conjectured that the key intermediate, $N$-phenyl- $N$ bromocarbonylhydrazine salt $4(\mathrm{R}=\mathrm{H})$, was formed from 4-bromo-3-phenylsydnone $(\mathbf{2}, \mathrm{R}=\mathrm{H})$ [also formed in situ], we prepared the latter from 3-phenylsydnone $(\mathbf{1}, \mathrm{R}=\mathrm{H})$ by bromination with $\mathrm{Br}_{2} / \mathrm{NaHCO}_{3}{ }^{24}$ and converted it into the salt $4(\mathrm{R}=\mathrm{H}, \mathrm{X}=\mathrm{Cl})$ using the method reported by Yeh et al. ${ }^{7}$ Treatment of the salt 4 with acetic anhydride gave the expected oxadiazolone $\mathbf{3 a}$ in reasonable yield (Scheme 2), a result which suggests strongly that the mechanism of the overall 3-phenylsydnone $(\mathbf{1}, \mathrm{R}=\mathrm{H})$ to $\mathbf{3 a}$ transformation involves a bromocarbonylhydrazine salt intermediate rather than the 1,3-dipolar cycloaddition mechanism proposed by Badami et al. Further support for this avenue is provided by Badami's observation that treatment of the 4bromosydnone $\mathbf{2}(\mathrm{R}=\mathrm{H})$ in acetic anhydride with $\mathrm{HBr}$ also yields the oxadiazolone product 3a. These results give a high degree of certainty to our mechanistic proposal delineated in Scheme 1 (path b).

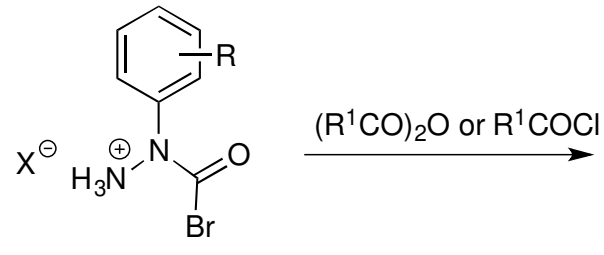

4

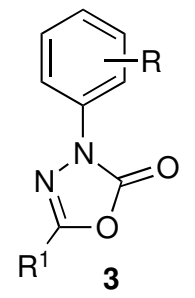

3

Scheme 2. Formation of 3,5-disubstituted-1,3,4-oxadiazol-2(3H)-ones. 
While we had been able to prepare oxadiazolinone 3a from the bromocarbonyl hydrazine salt $\mathbf{4}(\mathrm{R}=\mathrm{H}, \mathrm{X}=$ $\mathrm{Cl}$ ) as a test of our mechanistic proposal, as a practical synthetic avenue to oxadiazolinones, the method suffered from the same major deficiency inherent in the original sydnone 1 to oxadiazolinone 3a conversion (Scheme 1, path a), viz. the use of the anhydride as both reactant and solvent. Accordingly, we explored the transformation of $4(\mathrm{R}=\mathrm{H}, \mathrm{X}=\mathrm{Cl})$ into $3 \mathrm{a}$ using a variety of solvents and reduced amounts of acetic anhydride. From these studies, it was determined that the use of 1,2-dimethoxyethane (DME) as solvent gave the best results and the optimal protocol was with 2 eq. of acetic anhydride at $65^{\circ} \mathrm{C}$ for $2 \mathrm{~h}$. Extension to acid chlorides, including acetyl chloride, (Table 1, Entries 1-12) yielded the corresponding oxadiazolinones 3a-I in good yields and the overall method provides a novel approach to the latter. The present findings exhibit further the utility of 3-arylsydnones as precursors to useful heterocycles and, accordingly, given the rather efficient avenues to sydnones, ${ }^{25}$ including direct, one-pot avenues from $N$-substituted glycines, ${ }^{26}$ the process may find considerable utility.

Table 1. Preparation of 5-substituted-3-aryl-1,3,4-oxadiazol-2(3H)-ones 3 in DME

\begin{tabular}{ccccccc}
\hline Entry & $\begin{array}{c}\mathrm{R} \text { in } \\
\mathbf{1 - 4}\end{array}$ & $\mathrm{R}^{1}$ in $\mathbf{3}$ & Eq. $\mathrm{R}^{1} \mathrm{COCl}$ & Time (h) & Product & $\begin{array}{c}\text { Yield (\%) } \\
\text { of } \mathbf{3}\end{array}$ \\
\hline 1 & $\mathrm{H}$ & $\mathrm{CH}_{3}$ & 2 & 3.5 & $\mathbf{3 a}$ & 75 \\
2 & $\mathrm{H}$ & $\mathrm{BrCH}_{2}$ & 2 & 3.5 & $\mathbf{3 b}$ & $76^{\mathrm{a}}$ \\
3 & $\mathrm{H}$ & $\mathrm{CH}_{3} \mathrm{CH}_{2}$ & 2 & 3.5 & $\mathbf{3 c}$ & 83 \\
4 & $\mathrm{H}$ & $\mathrm{CH}_{3} \mathrm{CH}_{2} \mathrm{CH}_{2}$ & 2 & 3.5 & $\mathbf{3 d}$ & 51 \\
5 & $\mathrm{H}$ & $\mathrm{C}_{6} \mathrm{H}_{5}$ & 3.5 & 3.5 & $\mathbf{3 e}$ & 83 \\
6 & $\mathrm{H}$ & $4-\mathrm{CH}_{3} \mathrm{C}_{6} \mathrm{H}_{4}$ & 1.75 & 1.5 & $\mathbf{3 f}$ & 95 \\
7 & $\mathrm{H}$ & $4-\mathrm{CH}_{3} \mathrm{OC}_{6} \mathrm{H}_{4}$ & 1.75 & 1.5 & $\mathbf{3 g}$ & 97 \\
8 & $\mathrm{H}$ & $4-\mathrm{ClC}_{6} \mathrm{H}_{4}$ & 1.75 & 1.5 & $\mathbf{3 h}$ & 98 \\
9 & $\mathrm{H}$ & $4-\mathrm{BrC}_{6} \mathrm{H}_{4}$ & 2 & 3.5 & $\mathbf{3 i}$ & 99 \\
10 & $\mathrm{H}$ & $2-\mathrm{ClC}_{6} \mathrm{H}_{4}$ & 1.75 & 1.5 & $\mathbf{3 j}$ & 74 \\
11 & $4-\mathrm{Br}$ & $\mathrm{CH}_{3}$ & 1.75 & 1.5 & $\mathbf{3 k}$ & 81 \\
12 & $4-\mathrm{Cl}$ & $\mathrm{CH}_{3}$ & 1.75 & 1.5 & $\mathbf{3 l}$ & 81 \\
\hline
\end{tabular}

${ }^{a} 1-2 \%$ of $3, \mathrm{R}=\mathrm{Ph}, \mathrm{R}^{1}=\mathrm{ClCH}_{2}$ and $\mathrm{ICH}_{2}$ also present (GC/MS).

\section{Conclusions}

The conversion of 3-phenylsydnone $(\mathbf{1}, \mathrm{R}=\mathrm{H})$ into 5-methyl-3-phenyl-1,3,4-oxadiazol-2(3H)-one (3a) has been reinvestigated, the major impurity $(\mathbf{3 b})$ identified and the protocol improved to minimize the amount of the latter. A new mechanism via a bromocarbonylhydrazine salt intermediate $4(R=H)$ is proposed for the procedure and is supported by the observation that 4 reacts with acetic anhydride to yield $3 a$. The procedure has been extended to the use of acid chlorides and a novel synthesis of 5-substituted-3-aryl-1,3,4-oxadiazol2(3H)-ones 3 from $N$-aryl- $N$-bromocarbonylhydrazine salts $4(\mathrm{X}=\mathrm{Cl})$ has been developed. Most of the products $(3 a-j)$ are derived from 3-phenylsydnone $(\mathbf{1}, R=H)$ and, accordingly, the substituent at the 3-position in the 
products is consistently a phenyl group. However, as a proof of concept, two other sydnones $(\mathbf{1}, \mathrm{R}=4-\mathrm{Br}$ and 4- $\mathrm{Cl}$ ) were converted into the corresponding bromocarbonylhydrazines $4(\mathrm{R}=4-\mathrm{Br}$ and $4-\mathrm{Cl}, \mathrm{X}=\mathrm{Cl})$, and the latter reacted with acetic anhydride in DME to form the corresponding oxadiazol-2(3H)-ones $\mathbf{3 l}$ and $\mathbf{3 m}$, respectively. It is planned to extend this protocol to the use of other sydnone-derived bromocarbonylhydrazine salts and acid chlorides in order to better delineate the scope and limitations.

\section{Experimental Section}

General. 3-Phenylsydnone $(1, R=H),{ }^{27}$ 3-(4-bromophenyl)sydnone $(1, R=4-B r),{ }^{28}$ 3-(4-chlorophenyl)sydnone $(1, \mathrm{R}=4-\mathrm{Cl}){ }^{29}$ 4-bromo-3-phenylsydnone $(2, \mathrm{R}=\mathrm{H})^{2}$ and the $N$-phenyl- $N$-bromocarbonylhydrazine salts $(4, \mathrm{R}=$ $\mathrm{H}, 4-\mathrm{Cl}$ and $4-\mathrm{Br})^{7}$ were prepared as reported previously. Melting points were determined on a Mel-Temp melting point device and remain uncorrected. Infrared spectra were performed on a $\mathrm{KBr}$ salt plate and were taken on a Nicolet $6700 \mathrm{FTIR}$. NMR spectra were obtained on a Bruker Advance $300 \mathrm{MHz} \mathrm{NMR} \mathrm{in} \mathrm{CDCl}_{3}$ and are reported relative to tetramethylsilane as an internal standard. Column chromatography was accomplished either manually or on an Isco CombiFlash Separator System Sg100c. Thin layer chromatographic assessments were performed on silica gel. Elemental analyses were determined by Midwest Microlab LLC, Indianapolis, Indiana, U.S.A.

Improved procedure for the conversion of 3-phenylsydnone (1, $R=H$ ) into 5-methyl-3-phenyl-1,3,4oxadiazol-2(3H)-one (3a) using bromine in acetic anhydride. 3-Phenylsydnone (5.002 $\mathrm{g}, 0.031 \mathrm{~mol})$ was dissolved in $\mathrm{Ac}_{2} \mathrm{O}(25 \mathrm{~mL})$ and $\mathrm{Br}_{2}(5.271 \mathrm{~g}, 0.033 \mathrm{~mol})$ was added dropwise at rt with stirring. After $15 \mathrm{~min}$ the mixture was heated to $60{ }^{\circ} \mathrm{C}$ and, after a further $30 \mathrm{~min}$, cooled to rt and poured carefully over ice. The resultant precipitate was collected by filtration in vacuo, washed with water and dried to afford 3a as a light yellow solid, $4.917 \mathrm{~g}, 90.5 \%$. Recrystallization from 95\% EtOH gave the title compound as pale yellow crystals, $3.95 \mathrm{~g}, 73 \%$, identical (IR, NMR) to an authentic sample. ${ }^{4}$

General procedure for the synthesis of 5-substituted-3-aryl-1,3,4-oxadiazol-2(3H)-ones 3a-m from the corresponding bromocarbonylhydrazines $4(\mathrm{R}=\mathrm{H}, 4-\mathrm{Br}, 4-\mathrm{Cl}, \mathrm{X}=\mathrm{Cl})$. To the bromocarbonylhydrazine salt 4 (ca. $0.15 \mathrm{~g}$ ) in DME ( $8 \mathrm{~mL}$ ) was added the appropriate acid chloride (1.75-4 equivalents) dropwise with stirring. After heating at $65^{\circ} \mathrm{C}$ for $1.5-4 \mathrm{~h}$, the reaction mixture was allowed to cool to $\mathrm{rt}$ and then was poured carefully into saturated, aq $\mathrm{NaHCO}_{3}(30 \mathrm{~mL})$. The quenched mixture was warmed to $50{ }^{\circ} \mathrm{C}$ to reduce the volume of DME and then cooled to ice bath temperature. The resultant precipitate was filtered off, rinsed with ice-cold water, dried overnight in vacuo and recrystallized from 95\% EtOH to afford 3a-I in 51-99\% yield.

5-Methyl-3-phenyl-1,3,4-oxadiazol-2(3H)-one (3a). Reaction of $\mathrm{N}$-phenyl-N-bromocarbonylhydrazine hydrochloride $(4, \mathrm{R}=\mathrm{H}, \mathrm{X}=\mathrm{Cl})[0.150 \mathrm{~g}, 0.560 \mathrm{mmol}]$ with $\mathrm{AcCl}(0.080 \mathrm{~mL}, 1.12 \mathrm{mmol})$ in the general procedure for $3.5 \mathrm{~h}$ gave after work-up, colorless crystals, $0.075 \mathrm{~g} .75 \%, \mathrm{mp} 90-91{ }^{\circ} \mathrm{C}$, lit. ${ }^{4} \mathrm{mp} 92-3{ }^{\circ} \mathrm{C}$, identical (IR, NMR) to an authentic sample.

5-Bromomethyl-3-phenyl-1,3,4-oxadiazol-2(3H)-one (3b). Reaction of $N$-phenyl- $N$-bromocarbonylhydrazine hydrochloride $(4, \mathrm{R}=\mathrm{H}, \mathrm{X}=\mathrm{Cl})[0.159 \mathrm{~g}, 0.570 \mathrm{mmol}]$ with bromoacetyl chloride $(0.096 \mathrm{~mL}, 1.14 \mathrm{mmol})$ in the general procedure for $3.5 \mathrm{~h}$ gave after work-up, light tan crystals, $0.116 \mathrm{~g}, 76 \%, \mathrm{mp} 80-81{ }^{\circ} \mathrm{C} ; \mathrm{IR}(\mathrm{KBr}): 3042$, 2982, 1778, 1492, $960 \mathrm{~cm}^{-1} ;{ }^{1} \mathrm{H}$ NMR $\left(\mathrm{CDCl}_{3}\right)$ : 国 7.81-7.83 (d, 2H), 7.42-7.47 (t, 2H), 7.26-7.30 (t, $\left.1 \mathrm{H}\right), 4.28(\mathrm{~s}$, $2 \mathrm{H}) ;{ }^{13} \mathrm{C}-\mathrm{NMR}\left(\mathrm{CDCl}_{3}\right)$ : 152.0, 150.3, 135.6, 129.3, 126.5, 118.3, $17.6 \mathrm{ppm}$. Elemental analysis: calc. for $\mathrm{C}_{9} \mathrm{H}_{7} \mathrm{BrN}_{2} \mathrm{O}_{2}(256.07) \mathrm{C}: 42.38, \mathrm{H}: 2.77, \mathrm{~N}: 10.98$. Found C: $42.67, \mathrm{H}: 2.74, \mathrm{~N}: 10.96 \%$. 
5-Ethyl-3-phenyl-1,3,4-oxadiazol-2(3H)-one (3c). Reaction of $N$-phenyl- $N$-bromocarbonylhydrazine hydrochloride $(4, \mathrm{R}=\mathrm{H}, \mathrm{X}=\mathrm{Cl})[0.150 \mathrm{~g}, 0.560 \mathrm{mmol}]$ with propionyl chloride $(0.097 \mathrm{~mL}, 1.120 \mathrm{mmol})$ in the general procedure for $3.5 \mathrm{~h}$ gave after work-up, colorless crystals, $0.089 \mathrm{~g}, 83 \%, \mathrm{mp} \mathrm{58-60}{ }^{\circ} \mathrm{C}$, lit. ${ }^{4} \mathrm{mp} 60-61.5{ }^{\circ} \mathrm{C}$, identical (IR, NMR) to an authentic sample.

3-Phenyl-5-propyl-1,3,4-oxadiazol-2(3H)-one (3d). Reaction of $N$-phenyl- $N$-bromocarbonylhydrazine hydrochloride $(4, \mathrm{R}=\mathrm{H}, \mathrm{X}=\mathrm{Cl})[0.150 \mathrm{~g}, 0.560 \mathrm{mmol}]$ with butyryl chloride $(0.115 \mathrm{~mL}, 1.120 \mathrm{mmol})$ in the general procedure for $3.5 \mathrm{~h}$ gave after work-up colorless crystals, $0.059 \mathrm{~g}, 51 \%$, mp 56-57 ${ }^{\circ} \mathrm{C}$, lit. ${ }^{4} \mathrm{mp} 57.5-58.5{ }^{\circ} \mathrm{C}$, identical (IR, NMR) to an authentic sample.

5-Phenyl-3-phenyl-1,3,4-oxadiazol-2(3H)-one (3e). Reaction of $\mathrm{N}$-phenyl- $\mathrm{N}$-bromocarbonylhydrazine hydrochloride $(4, \mathrm{R}=\mathrm{H}, \mathrm{X}=\mathrm{Cl})[0.156 \mathrm{~g}, 0.600 \mathrm{mmol}]$ with $\mathrm{PhCOCl}(0.249 \mathrm{~mL}, 2.160 \mathrm{mmol})$ in the general procedure for 3.5 hours gave after work-up colorless crystals, $0.113 \mathrm{~g}, 83 \%, \mathrm{mp} 108-109{ }^{\circ} \mathrm{C}$, lit. ${ }^{9} \mathrm{mp} 109-110{ }^{\circ} \mathrm{C}$, identical (IR, NMR) to an authentic sample.

5-(4-Methylphenyl)-3-phenyl-1,3,4-oxadiazol-2(3H)-one (3f). Reaction of $\mathrm{N}$-phenyl- $\mathrm{N}$-bromocarbonylhydrazine hydrochloride $(4, \mathrm{R}=\mathrm{H}, \mathrm{X}=\mathrm{Cl})[0.151 \mathrm{~g}, 0.601 \mathrm{mmol}]$ with $p$-toluoyl chloride $(0.138 \mathrm{~mL}, 1.052$ $\mathrm{mmol}$ ) in the general procedure for $1.5 \mathrm{~h}$ gave after work-up, light tan crystals, $0.144 \mathrm{~g}, 95 \%, \mathrm{mp} 148-149{ }^{\circ} \mathrm{C}$, lit. ${ }^{9} \mathrm{mp} 155-156{ }^{\circ} \mathrm{C}$, identical (IR, NMR) to an authentic sample.

5-(4-Methoxyphenyl)-3-phenyl-1,3,4-oxadiazol-2(3H)-one $(3 \mathrm{~g})$. Reaction of $\mathrm{N}$-phenyl- $\mathrm{N}$-bromocarbonylhydrazine hydrochloride $(4, \mathrm{R}=\mathrm{H}, \mathrm{X}=\mathrm{Cl})[0.176 \mathrm{~g}, 0.698 \mathrm{mmol}]$ with anisoyl chloride $(0.167 \mathrm{~mL}, 1.222 \mathrm{mmol})$ in the general procedure for $1.5 \mathrm{~h}$ gave after work-up colorless crystals, $0.182 \mathrm{~g}, 97 \%, \mathrm{mp} 140-141{ }^{\circ} \mathrm{C}$, lit. ${ }^{23} \mathrm{mp}$ $137-138{ }^{\circ} \mathrm{C}$, identical (IR, NMR) to an authentic sample.

5-(4-Chlorophenyl)-3-phenyl-1,3,4-oxadiazol-2(3H)-one (3h). Reaction of $\mathrm{N}$-phenyl-N-bromocarbonylhydrazine hydrochloride $(4, \mathrm{R}=\mathrm{H}, \mathrm{X}=\mathrm{Cl})[0.159 \mathrm{~g}, 0.633 \mathrm{mmol}]$ with anisoyl chloride $(0.139 \mathrm{~mL}, 1.107 \mathrm{mmol})$ in the general procedure for $1.5 \mathrm{~h}$ gave after work-up, light tan crystals, $0.169 \mathrm{~g}, 98 \%, \mathrm{mp} 125-126{ }^{\circ} \mathrm{C}$, lit. ${ }^{9} \mathrm{mp}$ $118-119{ }^{\circ} \mathrm{C}$, identical (IR, NMR) to an authentic sample.

5-(4-Bromophenyl)-3-phenyl-1,3,4-oxadiazol-2(3H)-one (3i). Reaction of $N$-phenyl- $N$-bromocarbonylhydrazine hydrochloride $(4, \mathrm{R}=\mathrm{H}, \mathrm{X}=\mathrm{Cl})[0.153 \mathrm{~g}, 0.600 \mathrm{mmol}]$ with 4-bromobenzoyl chloride $(0.263 \mathrm{~g}, 1.200 \mathrm{mmol})$ in the general procedure for $3.5 \mathrm{~h}$ gave after work-up colorless crystals, $0.188 \mathrm{~g}, 99 \%, \mathrm{mp} 128-130{ }^{\circ} \mathrm{C}$, lit. ${ }^{9} \mathrm{mp}$ $123-124{ }^{\circ} \mathrm{C}$, identical (IR, NMR) to an authentic sample.

5-(2-Chlorophenyl)-3-phenyl-1,3,4-oxadiazol-2(3H)-one (3j). Reaction of $N$-phenyl- $N$-bromocarbonylhydrazine hydrochloride $(4, \mathrm{R}=\mathrm{H}, \mathrm{X}=\mathrm{Cl})[0.128 \mathrm{~g}, 0.51 \mathrm{mmol}]$ with 2-chlorobenzoyl chloride $(0.111 \mathrm{~mL}, 0.89 \mathrm{mmol})$ in the general procedure for $1.5 \mathrm{~h}$ gave after work-up, light tan crystals, $0.103 \mathrm{~g}, 74 \%, \mathrm{mp} 114-115^{\circ} \mathrm{C}$, lit. ${ }^{23} \mathrm{mp}$ $145-146{ }^{\circ} \mathrm{C}$; IR (KBr): 1785, 1480, 1029, 973, $749 \mathrm{~cm}^{-1} ;{ }^{1} \mathrm{H} \mathrm{NMR}\left(\mathrm{CDCl}_{3}\right)$ : ? $8.0(\mathrm{~d}, 1 \mathrm{H}), 7.91(\mathrm{~d}, 2 \mathrm{H}), 7.58(\mathrm{~m}, 2 \mathrm{H})$, $7.54(\mathrm{t}, 1 \mathrm{H}), 7.46(\mathrm{t}, 1 \mathrm{H}) 7.42(\mathrm{~d}, 1 \mathrm{H}), 7.31(\mathrm{t}, 1 \mathrm{H}) ;{ }^{13} \mathrm{C}-\mathrm{NMR}\left(\mathrm{CDCl}_{3}\right):$ 151.7, 150.3, 136.0, 132.9, 132.4, 131.6, $130.1,129.5,127.1,126.3,122.3,118.4 \mathrm{ppm}$.

3-(4-Bromophenyl)-5-methyl-1,3,4-oxadiazol-2(3H)-one (3k). Reaction of $\mathrm{N}$-(4-bromophenyl)- $\mathrm{N}$-bromocarbonylhydrazine hydrochloride $(4, \mathrm{R}=4-\mathrm{Br}, \mathrm{X}=\mathrm{Cl})[0.200 \mathrm{~g}, 0.605 \mathrm{mmol}]$ with $\mathrm{AcCl}(0.076 \mathrm{~mL}, 1.059 \mathrm{mmol})$ in the general procedure for $1.5 \mathrm{~h}$ gave after work-up, colorless crystals, $0.125 \mathrm{~g}, 81 \%, \mathrm{mp} 123-124{ }^{\circ} \mathrm{C}$, lit. ${ }^{5} \mathrm{mp}$ 124- $125{ }^{\circ} \mathrm{C}$, identical (IR, NMR) to an authentic sample.

3-(4-Chlorophenyl)-5-methyl-1,3,4-oxadiazol-2(3H)-one (3I). Reaction of $\mathrm{N}$-(4-chlorophenyl)- $\mathrm{N}$-bromocarbonylhydrazine hydrochloride $(4, \mathrm{R}=\mathrm{H}, \mathrm{X}=\mathrm{Cl})[0.160 \mathrm{~g}, 0.560 \mathrm{mmol}]$ with $\mathrm{AcCl}(0.070 \mathrm{~mL}, 0.979 \mathrm{mmol})$ in the general procedure for $1.5 \mathrm{~h}$ gave, after work-up, colorless crystals, $0.951 \mathrm{~g}, 81 \%, \mathrm{mp} 122-123{ }^{\circ} \mathrm{C}$, lit. ${ }^{5} \mathrm{mp}$ 121-122 ${ }^{\circ} \mathrm{C}$, identical (IR, NMR) to an authentic sample. 


\section{References}

1. Browne, D. L.; Harrity, J. P. A. Tetrahedron 2010, 66, 553 and loc. cit.

2. Kenner, J.; Mackay, K. Nature 1946, 158, 909. https://doi.org/10.1038/158909b0

3. Baker, W.; Ollis, W. D.; Poole, V. D. J. Chem. Soc. 1949, 313.

4. Stansfield, F. J. Chem. Soc. 1958, 4781.

5. Mallur, S. G.; Badami, B. V. II Farmaco 2000, 55, 65. https://doi.org/10.1016/S0014-827X(99)00103-2

6. Kamble, R. R.; Badami, B. V. J. Ind. Chem. Soc. 2002, 79, 629.

7. Kuo, C. N.; Wu, M. H.; Chen, S. P.; Li, T. P.; Huang, C. Y.; Yeh, M. Y. J. Chin. Chem. Soc. 1994, 41, 849. https://doi.org/10.1002/jccs.199400118

8. Jiang, L. L.; Tan, Y.; Zhu, X. L.; Wang, Z. F.; Zuo, Y.; Chen, Q.; Xi, Z.; Yang, G. F. J. Agric. Food Chem. 2010, 58, 2643.

https://doi.org/10.1021/if9026298

9. Guo, C. X.; Zhang, W. Z.; Zhang, N.; Lu, X. B. J. Org. Chem. 2017, 82, 7637. https://doi.org/10.1021/acs.joc.7b00963

10. Dickmann, R.; Melgarejo, J.; Loubiere, P.; Montagnon, M. Brighton Crop Protection Conference - Weeds 1997, 1, 51.

11. Mazouz, F.; Gueddari, S.; Burstein, C.; Mansuy, D.; Milcent, R. J. Med. Chem. 1993, 36, 1157. https://doi.org/10.1021/im00061a006

12. Chen, H.; Li, Z.; Han, Y. J. Agric. Food Chem. 2000, 48, 5312. https://doi.org/10.1021/if991065s

13. Ben Ali, F.; Verger, R.; Carriere, F.; Petry, S.; Muller, G.; Abousalham, A. Biochimie 2012, 94, 137. https://doi.org/10.1016/i.biochi.2011.09.028

14. Romine, J. L.; Martin, S. W.; Meanwell, N. A.; Gribkoff, V. K.; Boissard, C. G.; Dworetzky, S. I.; Natale, J.; Moon, S.; Ortiz, A.; Yeleswaram, S.; Pajor, L.; Gao, Q.; Starrett, J. E., Jr. J. Med. Chem. 2007, 50, 528. https://doi.org/10.1021/im061006n

15. Mamolo, M. G.; Zampieri, D.; Vio, L.; Fermeglia, M.; Ferrone, M.; Pricl, S.; Scialino, G.; Banfi, E. Bioorg. Med. Chem. 2005, 13, 3797.

https://doi.org/10.1016/i.bmc.2005.03.013

16. Patel, J. Z.; van Bruchem, J.; Laitinen, T.; Kaczor, A. A.; Navia-Paldanius, D.; Parkkari, T.; Savinainen, J. R.; Laitinen, T.; Nevalainen, T. J. Bioorg. Med. Chem. 2015, 23, 6335.

https://doi.org/10.1016/i.bmc.2015.08.030

17. Mazouz, F.; Lebreton, L.; Milcent, R.; Burstein, C. Eur. J. Med. Chem. 1990, 25, 659. https://doi.org/10.1016/0223-5234(90)90131-L

18. Mulvihill, M.; Nguyen, D. V.; MacDougall, B. S.; Weaver, D. G.; Mathis, W. D. Synthesis 2001, 1965.

19. Bancerz, M.; Georges, M. K. J. Org. Chem. 2011, 76, 6377. https://doi.org/10.1021/jo200820g

20. Patel, S. S.; Chandna, N.; Kumar, S.; Jain, N. Org. Biomol. Chem. 2016, 14, 5683. https://doi.org/10.1039/C5OB02667A

21. Wet-osot, S.; Phakhodee, W.; Pattarawarapan, M. J. Org. Chem. 2017, 82, 9923. https://doi.org/10.1021/acs.joc.7b01863 
22. Wang, Y.; Meng, X.; Yang, Y.; Zhang, L.; Guo, S.; Tang, D.; Li, Y.; Chen, B. Chem. Commun. 2015, $51,1905$. https://doi.org/10.1039/C4CC08731C

23. Ji, F.; Li, X.; Guo, W.; Wu, W.; Jiang, H. J. Org. Chem. 2015, 80, 5713. https://doi.org/10.1021/acs.joc.5b00664

24. Greco, C. V.; Pesce, M.; Franco, J. M. J. Heterocycl. Chem. 1966, 3, 391. https://doi.org/10.1002/ihet.5570030342

25. Applegate, J.; Turnbull, K. Synthesis 1988, 1011. https://doi.org/10.1055/s-1988-27791

26. Azarifar, D.; Ghasemnejad-Bosra, H. Synthesis 2006, 1123. https://doi.org/10.1055/s-2006-926380

27. Earl, J. C.; Mackney, A. W. J. Chem. Soc. 1935, 899. https://doi.org/10.1039/jr9350000899

28. Eade, R. A.; Earl, J. C. J. Chem. Soc. 1948, 2307. https://doi.org/10.1039/jr9480002307

29. Baker, W. ; Ollis, W. D.; Poole, V. D.; Barltrop, J. A.; Hill, R. A. W.; Sutton, L.E. Nature 1947, $160,366$. https://doi.org/10.1038/160366b0 